\title{
Recent drug regulatory affair and CTD module progress review for submission of pharmaceuticals product
}

Vaibhav Subhash Janjal 1, Snehal Ramdas Dhamodkar 2, Yogesh Pralhad Jadhao ${ }^{3}$, Sima Baburao Manmode 4 , Anil Keshav Pawar ${ }^{5}{ }^{*}$ and Harshada Ravindra Khandelwal 6

${ }^{1}$ Department of Quality Assurance Techniques, Dr. D. Y. Patil Institute of Pharmaceutical Science and Research, Pimpri, Pune, Maharashtra, India, 411018.

2 Department of Quality Assurance Techniques, AISSMS COLLEGE OF Pharmacy, Sangamvadi, Pune, Maharashtra, India, 41001.

${ }^{3}$ Department of Quality Assurance Techniques, Dr. D. Y. Patil College of Pharmacy, Akurdi, Pune, Maharashtra, India, 411044.

${ }^{4}$ Department of Pharmacology \&Toxicology, Bombay College of pharmacy, Kalina Santacruz east, Mumbai, Maharashtra, India 400098.

${ }^{5}$ Department of Quality Assurance, R. C. Patel Institute of Pharmaceutical Education and Research, Dist.- Dhule, Shirpur, Maharashtra, India, 425405.6

${ }^{6}$ Department of Pharmaceutics, R. C. Patel Institute of Pharmaceutical Education and Research, Dist.- Dhule, Shirpur, Maharashtra, India, 425405.

GSC Biological and Pharmaceutical Sciences, 2021, 16(03), 200-221

Publication history: Received on 18 August; revised on 24 September 2021; accepted on 26 September 2021

Article DOI: https://doi.org/10.30574/gscbps.2021.16.3.0279

\begin{abstract}
Regulatory Affairs (RA), also known as government affairs, is a relatively new profession that arose from governments' desire to protect public health by regulating the safety and efficacy of products such as pharmaceuticals, medical devices, pesticides, veterinary medicines, cosmetics, agrochemicals, and complementary medicines. Pharmaceutical regulatory affairs is concerned with the registration of pharmaceutical goods. All regulatory elements and guidelines connected to product filing are summarized in this evaluation. This study covers the whole CTD and eCTD submission process, as well as the modules that go with it. It also focuses on the key regulatory bodies across the world. Various roles of DRA departments, drug regulatory affairs professionals, the importance of drug affairs in pharmacy curriculum, emerging trends affecting regulatory strategy, regulatory affairs in product management, clinical trials, $R \& D$ and the drug approval process in the US, EU, and ROW market trends are discussed.
\end{abstract}

Keywords: Regulatory affairs; Regulatory Agencies; FDA; eCTD; Regulatory market

\footnotetext{
${ }^{*}$ Corresponding author: Anil Pawar

Department of Quality Assurance, R. C. Patel Institute of Pharmaceutical Education and Research, Dist.- Dhule, Shirpur, Maharashtra, India, 425405.

Copyright (C) 2021 Author(s) retain the copyright of this article. This article is published under the terms of the Creative Commons Attribution Liscense 4.0.
} 


\section{Graphical Extract}

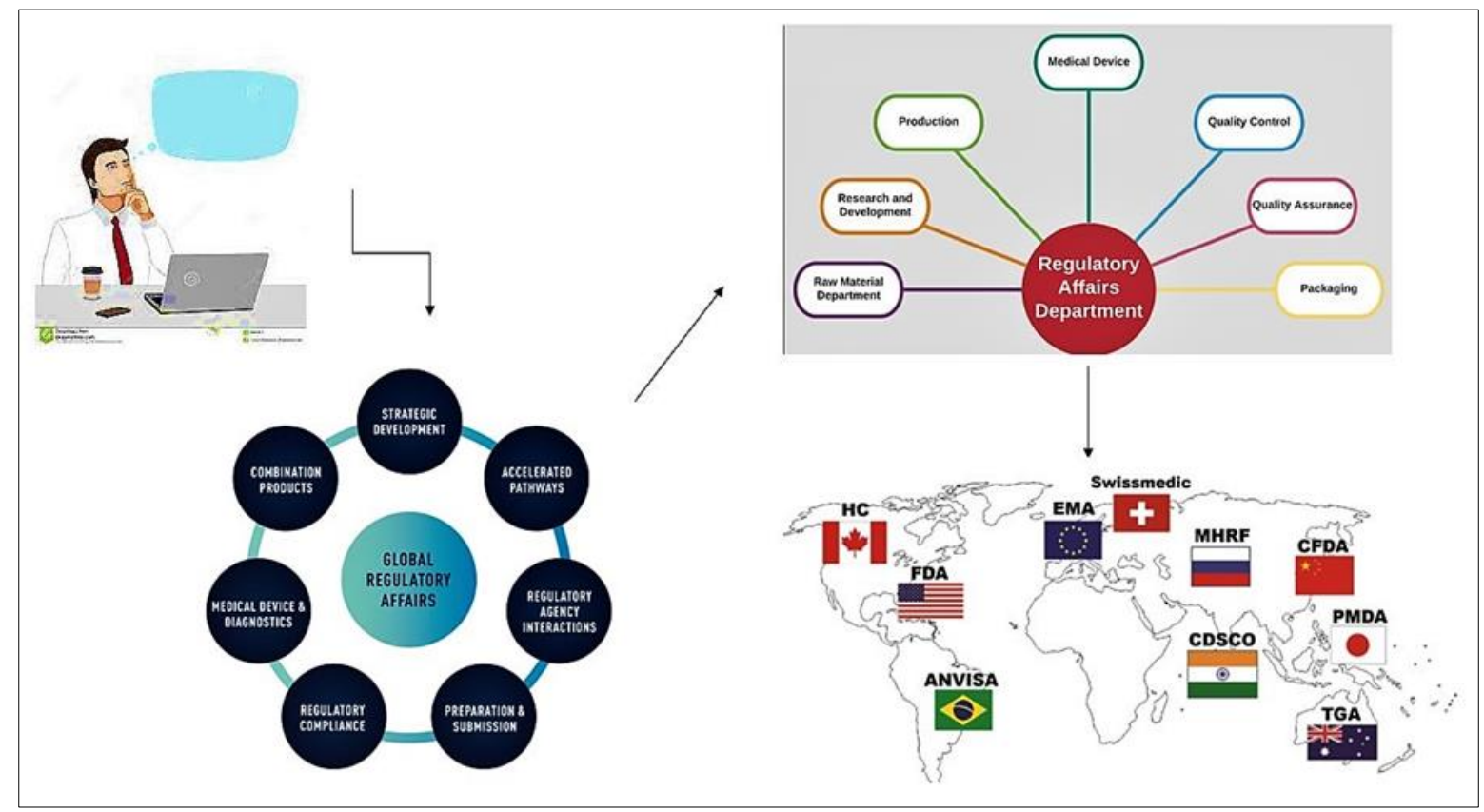

\section{Introduction}

Regulatory affairs (RA) is a career that works in industries that are regulated, such as pharmaceuticals, medical devices, veterinary medicine, cosmetics, and so on. At its core, the regulatory affairs profession is concerned with gathering, analysing, recording, and disseminating risk assessments and benefits of health care products to regulatory authorities and the general public throughout the world. All medications must fulfil the following requirements: high quality, safety, and efficacy. Regulatory affairs is a dynamic field that encompasses the scientific and legal elements of the New Drug Application (NDA), Investigated New Drug Application (INDA), and Market Authorization processes [1].

The Drug Development to Marketing Application (MAA) is all about drug development and marketing. Because of recent technological and scientific advancements, regulatory affairs now save data such as eCTD and CTD in different regulatory software available online, such as Pharma. READY: Freyr Global regulatory solution and service, including eCTD and eDMS submission software, master control registration, and Freyr Global regulatory solution and service. Food and Drug Administration (FDA), Therapeutic Goods Administration (TGA), Central Drug Standard Control Organization (CDSCO), and European Medicines Agency are examples of well-known regulatory bodies (EMEA ). The pharmaceutical sector is now highly structured, methodical, and compliant with worldwide regulatory requirements for the manufacture of chemicals, biological medicines, medical equipment, traditional herbal items, and cosmetics for human and animal use. Every regulatory system has been subjected to a set of conditions that have resulted in the current well-defined, tightly regulated regulatory framework. This resulted in the development of a system for the production and distribution of safe, effective, and high-quality medicines. As the pharmaceutical business has grown, the laws in each region have gotten increasingly complicated, necessitating the hiring of regulatory specialists. Regulatory affairs specialists in the pharmaceutical business serve a critical role in ensuring that all pharmaceutical products adhere to industry rules. Pharma regulatory affairs professionals work not only in the initial application process for new or generic medications, but also throughout the licencing and marketing phases, ensuring that all activities and products satisfy the appropriate safety and effectiveness requirements. Pharma professionals serve as a liaison between pharmaceutical firms and regulatory agencies such as the Food and Drug Administration (FDA) and the European Union in the majority of situations. For any new pharmaceutical product coming into the market, it will be required about 10 - 15 years, spending much time and many million Dollars, but take an example of COVID -19 Disease ,Coronavirus disease (COVID-19), is an infectious disease caused by a newly discovered coronavirus (SARS-CoV-2), which has spread rapidly throughout the world. In March 2020, the World Health Organization (WHO) declared the COVID-19 outbreak a pandemic. The pandemic has severely ravaged health systems, and economic and social progress globally [2].

For the development of a Corona virus vaccine, regulatory authorities, WHO, ICH guidance, and the governments of respective countries have taken strong actions under the norms and regulations to make vaccines for Emergency Use 
Authorization, and have developed corona virus vaccines country-by-country, e.g. COVISHELD, COVAXIN ( CDSCO , India ) COVID MODERNA -19 ( U S FDA ) Pfizer-BioNTech COVID 19 (US FDA) is an incredible surprise in the pharmaceutical business, with vaccines created in little over a year. The regulatory affairs system has a huge influence on the world. The global market is separated into two categories: regulated and semi-controlled markets. In product management, clinical trials, and R\&D, drug regulatory affairs is a research field. [3].

\section{Role of Regulatory Affair Department}

The regulatory affairs (RA) department of the pharmaceutical industry is in responsibility of obtaining permission for new pharmaceutical medicines and ensuring that approval is maintained for as long as the firm desires. The following areas are under the control of regulatory affairs practitioners (also known as regulatory professionals): Assuring that their firms adhere to all applicable regulations and laws. It is the responsibility of a regulatory affairs professional to function as a point of contact for regulatory authorities. Ensure compliance with all applicable CGMP, ICH, GCP, and GLP regulations, legislation, and laws by preparing well-organized paperwork. They contribute experience and regulatory knowledge to the translation of regulatory standards into practical, feasible plans.

Regulatory affairs is critical in the pharmaceutical business since it is involved in all phases of medication development as well as drug clearance and marketing. Pharmaceutical companies use all of the information acquired throughout the research and development procedures to register and sell medicines. To ensure the drug's safety and efficacy in people, pharmaceutical companies must follow strict regulations and standards during the production process.

Right from the start of a product's development, regulatory affairs experts provide strategic and technological guidance to R\&D, Production, and Quality Control departments, among others, contributing significantly both financially and scientifically to the advancement of a development initiative and the enterprise as a whole. A new pharmaceutical product can take up to 15 years to develop and put on the market, and during that period, many difficulties might arise owing to technical advancements and changing regulatory environments. Regulatory specialists help the company avoid problems caused by inappropriate records, incorrect statistical reasoning, or poor proof presentation [4].

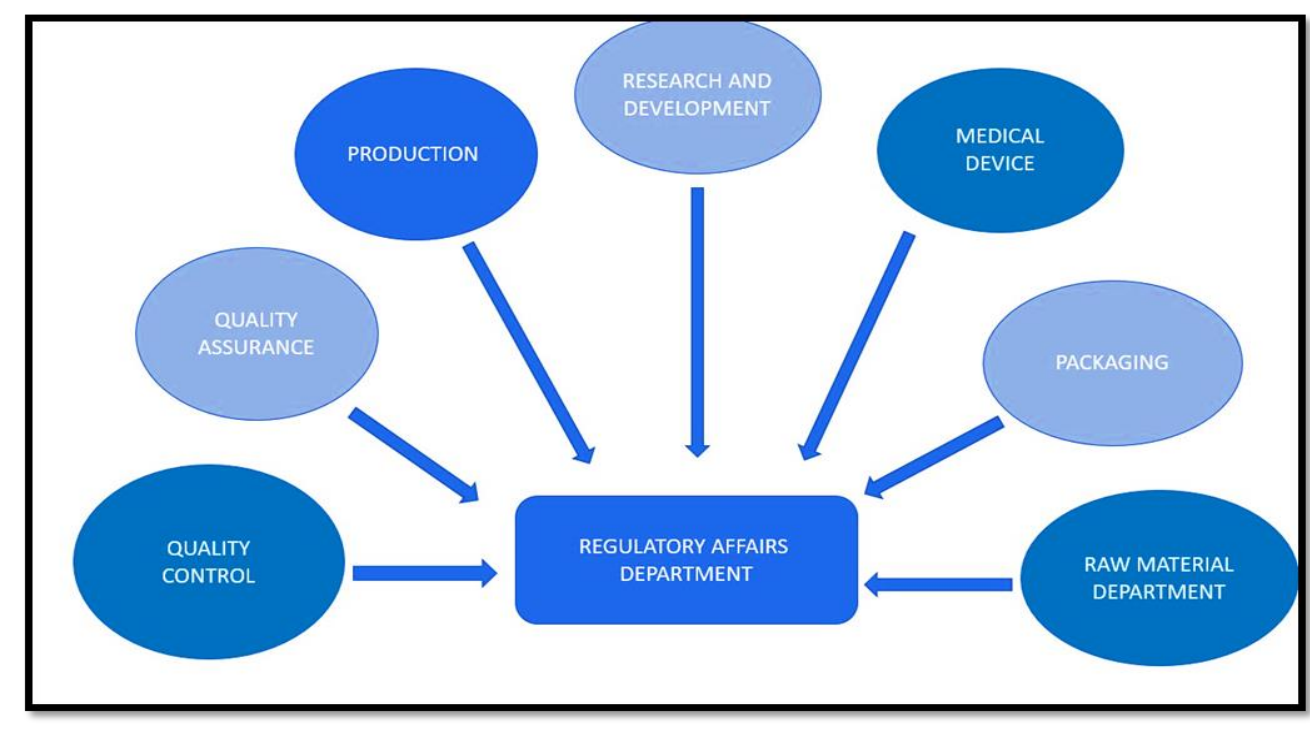

Figure 1 Roles of Regulatory affair department

\subsection{Professionals in regulatory affairs work for a variety of departments, including}

\subsubsection{Preclinical research}

Pharmacology and toxicology testing was used to assess potential drug candidates in preclinical studies.

\subsubsection{Clinical trials}

Evidence gathering, mathematical interpretation, and paper writing are all aspects of clinical research. 


\subsubsection{Manufacturing}

Extensive safeguards are in place to ensure that goods are clean and efficient.

\subsubsection{Quality Control}

Is the process of analyzing all materials for purity, safety, potency, and quality.

\subsubsection{Quality assurance}

Entails overseeing activities such as defect audits, auditing, complaints, and record processing.

\section{Need of Regulatory Affairs in Pharmacy curriculum}

Pharmaceutical biotechnology and medical device research and development are two of the world's most tightly regulated sectors. India will continue to develop. In order to fulfil the present needs of companies to compete on a worldwide basis, regulatory relations specialists are in great demand in the pharmaceutical sector. Regulatory affairs professionals operate as a link between the pharmaceutical sector and international regulatory agencies. They must be well-versed in all of the rules. The demand for current pharmaceutical sector norms to be adopted into the norm is growing among administrative authorities' regulations, procedures, and recommendations.

The curricula of pharmacy schools should prepare students to give the most up-to-date knowledge to industry. The purpose of this study is to discuss the significance of regulatory education. All learning resources, accessible lectures, syllabus information, and job vacancies in regulatory affairs are available. India's pharmaceutical sector is growing at a rapid pace, and regulatory affairs professionals are in high demand to help firms compete worldwide. Regulatory affairs professionals operate as a link between the pharmaceutical sector and international regulatory agencies. They must be well-versed in the regulatory agencies' rules, legislation, protocols, and recommendations. There is an increasing need to integrate existing pharmaceutical industry standards into pharmacy college standard curriculum to train students for the latest technologies to support the industries [5].

\section{Drug regulatory Affair professional}

The duty of the Regulatory Affairs expert is to keep up with the continuously changing rules in all of the countries where the company wishes to sell its products. Regulatory Affairs experts are in charge of presenting registration paperwork to regulatory authorities and doing all necessary talks in order to keep the items on the market. They give strategic and technological assistance at the highest levels of their enterprises from the beginning of a product's development, contributing considerably both financially and clinically to the advancement of a development effort and the firm as a whole. [6].

The Regulatory Affairs Department's duties are listed below:

- $\quad$ Stay up to date on international regulations, rules, and consumer behavior.

- Stay up to date with a company's product line

- Ascertain that a company's goods adhere to existing legislation.

- The Regulatory Affairs professional's role is to stay on top of the constantly evolving regulations in all of the countries where the organization wants to sell its goods. They will provide legal and technical guidance, as well as gather, collate, and review the scientific evidence generated by their research and development colleagues.

- Develop a regulatory plan with all necessary regulatory submissions for domestic, foreign, and contract programs.

- In collaboration with the agency, coordinate, plan, and review all relevant documentation, such as dossiers, and send them to regulatory authorities within a defined time.

- Develop and study RA-related SOPs. BMR, MFR, shift control, and other related records are reviewed.

- Keep track of the status of all registrations.

- Keep track of accepted applications and registration fees charged in exchange for DMFs and other records.

- Impart training to R\&D, Pilot plant, ADL, and RA. Team members on current regulatory requirements. 
- Have a duty to provide physicians and other healthcare professionals with accurate and complete information about the quality, safety, and effectiveness of the product.

\section{What makes a good Regulatory Affairs professional?}

While biotechnology degrees are becoming increasingly essential, the bulk of regulatory practitioners have a research background, generally in biological sciences or pharmacy. Some people desire to acquire a law degree to go along with their other qualifications. It's critical to be able to deal with data from a range of study disciplines and to grasp new concepts and technological expertise quickly. Analyzing questions and giving written and oral evidence before a jury of experts, which may include scientists, pharmacists, physicians, and government attorneys, needs a deep understanding of both legal and technical issues.

Extreme vigilance is essential while suggesting and implementing the strategy and tactics required to obtain marketing approval in a manner that pleases the authorities in order to protect the company's best interests. Great attention must be exercised if the company's condition is to be presented to the authorities in the best possible light. It must be accomplished without obscuring the data, allowing regulators to make an informed and genuine conclusion regarding the product's safety, efficacy, and consistency.

Regulatory practitioners must constantly use prudence in their job. A strong leader possesses two qualities: integrity and the drive to encourage others. The characteristics of trust and confidence are essential. Project management skills assist them in reaching their ambitious goals. They will participate in multidisciplinary teams and, if required, lead them. They are capable of performing under pressure while inspiring and encouraging others to do the same [7].

\section{Regulatory Affairs in $R$ and $D$}

The affairs team partners with R\&D and FR\&D to develop novel solutions that address evolving technological and regulatory trends in order to minimise time to market. The new products are expected to increase sales; losses from delayed marketing will be compensated by considerable commodity income and benefit increases over time.

By getting quick approval from regulatory bodies and avoiding difficulties in the process, adaptive clinical trial techniques can assist to speed up the introduction of new medications and eliminate costly blunders and time lags. Professionals in regulatory affairs engage with marketing and R\&D to develop cutting-edge technologies that take advantage of new technical and regulatory improvements while reducing time to market.

Small reductions in time to market result in significant gains in commodity sales and profitability, with new products expected to contribute significantly to the company's bottom line. Adaptive clinical trial strategies, quick regulatory approval, and avoiding procedural hazards will all assist to accelerate the introduction of new medications while decreasing costly errors and time delays [8].

\section{Regulatory affairs in Clinical Trials}

Regulatory affairs professionals act as the primary contact between an organisation and worldwide regulatory organisations such as official bodies (US FDA, CDSCO, MCCA, TGA, etc.). Their role is to offer quick evaluations of new data gathered during trials and to help in the approval of new medications as necessary by local regulatory bodies in their respective states.

The RA team devises strategies to prevent delays and communicates clinical trial data to regulatory authorities in order to gain quick approval and reduce the time it takes for novel compounds to be authorised. The capacity of the RA professional to acquire, evaluate, and disseminate knowledge regarding the risks and benefits of health products helps regulatory authorities, medical and educational services, and the general public. RA's operational tasks include ensuring that all parties are aware of and comply with government requirements, market-driven needs, and developing research conventions [9].

\section{Regulatory affairs in Product management}

Drug goods are tightly regulated in compared to other channels. These rules are usually maintained and managed by regulatory bodies; these bodies generally guide substance formulation based on IND/NDA standards until the approval 
phase is complete; once the approval process is complete, these bodies focus on the medication post-market properties as well as the Pharmacovigilance characteristics of the drug product; and it frequently reminds the drug

The entire job of Regulatory Affairs goes beyond substance registration; they also give strategic and technology guidance to firms at the highest levels. They play a significant role in everything from product development to promotion and post-marketing efforts. Their guidance at all stages of the development process, both in terms of regulatory and technological requirements, saves time and money for enterprises [10].

\section{Importance of Regulatory Affairs}

In today's fast-paced environment, a product's and hence a company's success is dependent on minimising the time it takes to reach a consumer. As a result, the Regulatory Affairs activities of the firm must be effectively handled. Inadequate data reporting can stymie a timely constructive evaluation of a marketing application. A new drug might have cost millions of Euros or pounds to develop, and even a three-month delay in bringing it to market can be costly.

A product recall might be forced if all available data is not recorded or if a product is released with improper labelling. Any occurrence might result in a revenue loss of millions of dollars, as well as a loss of investor, healthcare provider, and patient confidence. Regulatory Affairs is frequently a company's initial point of contact with government regulators [2].

\section{Global market: Pharma market broadly divided into two types Regulated market and Semi- regulated market}

\subsection{Regulated Market}

EU (UK, Germany, France, Ireland, Sweden etc.), US, Japan, Canada, Australia, New Zealand, South Africa.

\subsection{Semi-regulated Market (ROW Countries)}

- African Countries: Algeria, Zambia, Ethiopia, Ghana, Kenya, Mozambique, Malawi, Nigeria, Namibia, Sierra, Leone, Tanzania, Zimbabwe etc.

- Asia: Sri Lanka, India, Bangladesh, And And ASEAN: having groups of 10 Countries - Vietnam, Malaysia, Philippines, Singapore, Thailand, Indonesia, Laos, Cambodia, Brunei Darussalam, Myanmar.

- $\quad$ Latin America: Brazil, Panama, Peru, Mexico, Argentina, Guatemala, Chile, Dominican Republic.

- Middle East countries: also called Gulf Co-operation Council countries i. e. Kuwait, Bahrain, Qatar, Oman, Saudi Arabia, and UAE.

- Common Wealth of independent States (CIS): Ukraine, Russia, OFSU (America, Azerbaijan, Belarus, Georgia, Kazakhstan, Kirghizstan, Turkmenistan etc [11].

\section{Worldwide Regulatory Agencies}

Table 1 List of Worldwide Regulatory Agencies

\begin{tabular}{|l|l|l|}
\hline Region & Country name & Regulatory agencies/ body \\
\hline \begin{tabular}{l} 
Australia / New $\begin{array}{l}\text { Zealand } \\
\text { North America }\end{array}$ \\
\cline { 2 - 3 }
\end{tabular} & Australia & Therapeutic goods Administration (TGA) \\
\cline { 2 - 3 } & Canada & MEDSAFE \\
\hline \multirow{2}{*}{ Europe } & USA & Health Canada \\
\cline { 2 - 3 } & America & Food and Drug Administration (FDA) . \\
\cline { 2 - 3 } & Austria & Scientific Centre for Drug and Medicinal Technology Expertise. \\
\cline { 2 - 3 } & Bulgaria & Agency for Health and Food Safety (AGES). \\
\cline { 2 - 3 } & Belgium & Federal Agency for Medicines and Health Products. \\
\hline
\end{tabular}


GSC Biological and Pharmaceutical Sciences, 2021, 16(03), 200-221

\begin{tabular}{|c|c|c|}
\hline \multicolumn{3}{|r|}{ Ministry of Health } \\
\hline & Croatia & Agency for Medical Products and Medical Devices of Croatia. \\
\hline & Czech Republic & State Institute for Drug Control \\
\hline & Denmark & Danish Medicines Agency. \\
\hline & Estonia & State agency of Medicines \\
\hline & Finland & Finish Medicines Agency. \\
\hline & Germany & Federal Institute for Drugs and Medical Devices. \\
\hline & Georgia & Regulation agency for Medical and Pharmaceutical Activities \\
\hline & Greece & National Organization for Medicines \\
\hline & Hungary & National institute of pharmacy. \\
\hline & Ireland & Irish Medicines Board. \\
\hline & Iceland & Icelandic Medicines Agency. \\
\hline & Italy & National institute of Health. \\
\hline & Lithuania & State Medicines Control Agency \\
\hline & Luxembourg & Ministry of health. \\
\hline & Malta & Maltese Medicines Authority. And Moldova Medicines Agency. \\
\hline & Netherlands & Medicines evaluation Board. \\
\hline & Norway & Norwegian Medicines Agency \\
\hline & Portugal & National Authority of Medicines and Health Products \\
\hline & Romania & National Medicines Agency \\
\hline & Poland & $\begin{array}{l}\text { The Office for Registration of Medicinal Products, Medical Devices } \\
\text { and Biocidal product }\end{array}$ \\
\hline & Russia & Ministry of Health of the Russian federation. \\
\hline & Serbia & Medicines and Medical Devices Agency of Serbia. \\
\hline & Slovakia & State Institute for drug Control. \\
\hline & Slovenia & Ministry of Health. \\
\hline & Spain & Spanish Medicines Agency. \\
\hline & Sweden & Medical Products Agency. \\
\hline & Switzerland & Swiss Agency for Therapeutic Products. \\
\hline & Ukraine & Ministry of Health. \\
\hline & United Kingdom & Medicines and Healthcare regulatory Agency (MHRA). \\
\hline Middle East & Egypt & Ministry of Health \\
\hline & Iran & Ministry of Health \\
\hline & Israel & Ministry of Health \\
\hline & Jordan & Jordan Food and Drug Administration \\
\hline & Saudi Arabia & Saudi Food and Drug authority. \\
\hline Central /South & Argentina & ANMAT \\
\hline & Brazil & Agencia Nacional de Vigilancia Sanitaria. \\
\hline
\end{tabular}


GSC Biological and Pharmaceutical Sciences, 2021, 16(03), 200-221

\begin{tabular}{|c|c|c|}
\hline & Columbia & $\begin{array}{l}\text { Instituto Nacional de Vigilancia Medicamentos y Alimentos. } \\
\text { (INVIMA) }\end{array}$ \\
\hline & Jamaica & Ministry of Health. \\
\hline \multirow[t]{13}{*}{ Asia- Pacific } & India & Central drug Standards Control Organization (CDSCO). \\
\hline & Bangladesh & Bangladesh Indonesia - POM (pengawas Obat Dan Makanan) \\
\hline & Japan & Ministry of Health, Labor and Welfare. (MHLW). \\
\hline & South Korea & Korean Food and Drug Administration. (KFDA). \\
\hline & Laos & Food and drug Department. \\
\hline & Malaysia & Ministry of Health. (MOH). \\
\hline & Nepal & Department of Health Administration. \\
\hline & Philippines & Department of Health. (DOH). \\
\hline & Singapore & Health Sciences Authority (HAS). \\
\hline & Sri-Lanka & Ministry of Health. \\
\hline & $\begin{array}{l}\text { Taiwan (Republic of } \\
\text { china) }\end{array}$ & Taiwan food and Drug Administration \\
\hline & Thailand & Food and Drug Administration of Thailand. \\
\hline & Vietnam & Drug Administration of Vietnam. \\
\hline \multirow[t]{10}{*}{ Africa } & Algeria & Ministry of Health and Population. \\
\hline & Botswana & Ministry of Health. \\
\hline & Ghana & Food and Drug Authority. \\
\hline & Kenya & Pharmacy and Poison Board. \\
\hline & Morocco & Ministry of Health. \\
\hline & Rwanda & Ministry of Health. \\
\hline & South Africa & Medicines Control Council. (MCC). \\
\hline & Swaziland & Ministry of Health \\
\hline & Tanzania & Tanzania Food and Drug Authority. (TFDA). \\
\hline & Uganda & National Drug Authority \\
\hline
\end{tabular}

\section{The Central Drugs Standard Control Organization}

The Central Drugs Standard Control Organization (CDSCO) of India is the National Regulatory Authority (NRA). Which is a component of India's Ministry of Health and Family Welfare's Directorate General of Health Services. FDA Bhawan, Kotla Road, New Delhi 110002, is the headquarters, with six zonal offices, four sub zonal offices, thirteen port offices, and seven laboratories scattered around the nation.

CDSCO is in charge of approving drugs, conducting clinical trials, establishing drug requirements, monitoring the quality of drugs imported into the country, and coordinating the activities of State Drug Control Organizations by providing expert guidance in order to achieve uniformity in the application of the 1940 Drug and Cosmetic Act [12].

\section{Vision}

To protect and promote India's public health. 


\section{Mission}

To ensure the Safety, Effectiveness, and efficiency of medicines, Cosmetics and Medical devices in order to protect and improve public health.

\subsection{CDSCO's Key Responsibilities include}

Drug imports, approval of new products and clinical trials, meetings of the Drugs Consultative Committee (DCC) and Drug Technical Advisory Board (DTAB), and approval of such licences as the central License Approving Authority are all regulated by the CDSCO headquarters.

\subsection{Responsibilities}

State authorities are primarily responsible for regulating the manufacture, sale, and distribution of drugs under the Drug and Cosmetics Act, whereas central authorities are responsible for approving new drugs, conducting clinical trials in the country, establishing drug standards, inspecting imported drugs for quality, and coordinating the activities of State Drug Control Organizations [13].

The Indian Drug controller General is in charge of approving licenses for specific drug categories such as blood and blood products, intravenous fluid, vaccines, and sera.

Table 2 Functions of CDSCO

\begin{tabular}{|c|l|}
\hline Sr. no. & \multicolumn{1}{c|}{ Functions of CDSCO } \\
\hline 1 & Approval of new drugs and clinical trials. \\
\hline 2 & Amendment of D \& C Act and Rules. \\
\hline 3 & Import Registration and Licensing. \\
\hline 4 & $\begin{array}{l}\text { License approving of blood banks, LVPs vaccines, r-DNA products, and some } \\
\text { medicinal devices (CLAA scheme). }\end{array}$ \\
\hline 5 & Banning of Drugs and Cosmetics. \\
\hline 6 & Grant of Test License, Personal License, NOCs for Export. \\
\hline 7 & Testing of new drugs. \\
\hline 8 & $\begin{array}{l}\text { Oversight and market Surveillance through inspectorate of center over and } \\
\text { above the State Authority }\end{array}$ \\
\hline
\end{tabular}

\section{Drug approval process in India}

The Drug and Cosmetic Act 1940 and Rules 1945 were passed by India's parliament to regulate the import, manufacturing, transport, and sale of pharmaceuticals and cosmetics. The Central Drugs Standard Control Organization is led by the Drugs Controller General (DCGI) (CDSCO). The Indian government modified the Drug and Cosmetics Rules of 1945 in 1988, creating Schedule Y.

When a business in India wants to develop or import a new medicine, it must fill out Form 44 and transmit the data needed under Schedule Y of the Drugs and Cosmetics Act 1940 and Rules 1945 to the licencing body (DCGI). It must conduct clinical trials in accordance with the standards specified in Schedule $Y$ and use the results of those trials in the manner outlined in Schedule Y to show its efficacy and safety in the Indian community [14].

The need for local clinical trials in India is based on the drug's status in other countries. Generally, Phase III trials are expected if the medication has already been accepted in other countries. In India, phase I trials are only permitted if data from other countries is present. If the medicine has particular significance to a health issue in India, such as malaria or tuberculosis, DCGI will give permission to run Phase 1 trials in India.

When conducting bioavailability and bioequivalence testing, the BABE criteria should be followed. Aside from safety and efficacy data, thorough information on the drug's commercial status in other countries is necessary. Documents concerning the medicine, samples and testing processes, product monographs, and labelling must also be requested. 
Clinical study approval in India typically takes three months. Clinical trials can be filed with the Clinical Studies Registry of India (CTRI), which keeps track of both the trials and the people who take part in them. The Drugs and Cosmetics Laws of 1945 provide the following guidelines:

The below are the provisions of the 1945 Drugs and Cosmetics Rules:

- Rule 122 - A: Request for New Drug Import Approval

- Rule 122-B: application for permission to import a new medication that is not on Schedule C or C. (1).

- Permission to import or export fixed dosage combinations (Rule 122-D).

- Rule 122 - DA: Request for approval to perform clinical trials for a new drug or an investigational new drug.

- DAB: Compensation in the event of injuries or death during clinical trials (Rule 122).

The Drugs and Cosmetics Act has been amended to include definitions for Phase I-IV trials as well as specific obligations for inspectors and sponsors. In 2006, the clinical trials were further split into two groups. Clinical studies can be performed in other markets with qualified and advanced regulatory regimes in one category (category A), while the others fall under another category (category B) Other than A. Clinical trials in category A (approved in the United States, the United Kingdom, Switzerland, Australia, Canada, Germany, South Africa, Japan, and the European Union) are eligible for quick tracking in India, with approval expected within eight weeks.

Class B clinical trials are scrutinized more closely and are approved in 16 to 18 weeks. DCGI should be contacted for an application to perform clinical trials in India, as well as data on chemistry, processing, monitoring, and animal tests. Add the trial protocol date, investigator brochures, and informed consent documents. The ethical committee must have a copy of the document, and clinical trials will only begin after DCGI and the ethical committee have given their consent [13].

\subsection{Stages of Approval}

- The submission of a Clinical Trial proposal for the purpose of determining the safety and effectiveness of a product.

- Conditions for the clearance of new medicines.

- Improvements in biological products after approval: cost, protection, and effectiveness records.

- Preparation of high-quality data for new drug submission approval of a medication. The CTD format has been adopted by the vast majority of nations. As a result, CDSCO has agreed to use the CTD format for technical specifications for prescription product registration for human use.

\section{U. S. FDA (United States Food and Drug Administration)}

\subsection{FDA mission}

The Food and Drug Administration is liable for protecting the public health by ensuring the safety, efficacy, and security of Human and veterinary drugs, medical devices, and biological products and by ensuring the safekeeping of our nation's food supply, cosmetics and products that emit radiation.

FDA also plays a crucial role in the regulation of manufacturing, marketing, and distribution of tobacco products to protect public health and to reduce tobacco use by minor's i. e the person under the age of full legal responsibility. FDA also focuses on to improve the public health by providing more effective use, safer, and more affordable medical products. This can be achieved by using accurate science based information [15].

\subsection{FDA Approved Product}

The Food and Drug Administration of the United States has approved and regulated the following products: Bottled water is used in diet supplements, food additives, infant formulae, and other food items (although U.S Department of Agriculture plays a lead role in a regulating aspect of some meat, poultry, and eggs products). Prescription drugs (including brand-name and generic), biologics, and nonprescription (over-the-counter) medicines are examples of medications. Vaccines for people- blood and blood derivatives, products for cellular and gene therapy allergens in tissues and tissue products. Medical equipment, such as: Objects as basic as tongue depressors and bedpans, heart pacemaker and dental devices are example of complex technologies. Prosthetics and surgical implants. Radiation- 
emitting electronic products include: X-ray equipment microwave ovens, items with lasers, ultrasonic therapy apparatus, vapor lamp made of mercury, the sunlamps. Cosmetics, for example: Colorants used in cosmetics and other personal care products such as skin moisturizers and cleansers, nail polish, and perfume. Veterinary medicines, such as: Pet food is fed to animals. Veterinary pharmaceuticals and applications. Products containing tobacco, such as: Roll your own tobacco, cigarettes, tobacco that does not produce smoke.

\subsection{Drug approval process in US}

Vaccines for individuals, including blood and blood derivatives, cellular and gene therapy products, and allergens in tissues and organs The United States has some of the world's strictest drug approval standards. Drug approval criteria in the United States are stringent. Many individuals consider nations to be the most difficult in the world. The adoption of the United States Drug Act in 1820 marked the start of a new era in drug regulation in the United States. It was decided to construct the United States Pharmacopoeia. Congress approved the first Food and Drug Act in 1906, mandating medications to satisfy official strength and purity requirements. create products. However, due to the great depression in1937, the Federal food, Drug, ad Cosmetics Act (of 1938) and Sulfanilamide Tragedy was enacted, which included new Requirement for the approval of new drugs (medicines).Demonstrated to be safe before marketing.

Vaccines for individuals, including blood and blood derivatives, cellular and gene therapy products, and allergens in tissues and organs The FDA's new medication approval procedure includes two stages: United Clinical Trials (CT) and New Drug Application (NDA) approval. A new drug application regulates the new medication product. NDA (NonDisclosure Agreement) (National Defense Authorization Act). Such applications have been accepted for analysis in eCTD at this time. The approval procedure begins once an investigational new drug (IND) application is submitted to the FDA. The Drug Laws and Regulations in the United States The United States Pharmacopoeia (USP) was founded in 1820 to provide a standard for medication strength and purity [16].

The Food and Drugs Act (1906) is a major landmark in the history of US drug law. It stipulates that drugs must satisfy certain criteria. Food, Drug, and Cosmetics Acts of 1938: After that, it was enacted. To demonstrate the safety of a medication before it is approved, the sulfanilamide tragedy occurred.it has been advertised.

In 1962, the Kefauver-Harris Amendment was passed. Following the thalidomide tragedy, it was moved. It is necessary for medication manufacturers to show that their product is both safe and dependable. Every company should send out a bad message. The FDA has received the communication. The Orphan Drug Act of 1973 allows for tax deductions for medications judged to be uncommon. Companies are working on developing orphan medicines. It is concerned with arrests made under the 1992 Generic Drug Enforcement Act. The generic drug control Act deals with convictions related to ANDA authorization (1902). There are several changes to the FDA Modernization Act of 1997 (FDAMA). The Food, Drug, and Cosmetics Act governs the manufacturing and distribution of food, medicines, and cosmetics. User fees are being calculated, and the approval process is being accelerated.

\section{Investigational New Drug Application (INDA)}

An FDA application is filed prior to human inspection. It goes through the chemistry, manufacturing, and quality assurance in great depth. The following information must be provided in the IND application: (1) Toxicology and Pharmacology Research in Animals. (2) Clinical investigators and procedures. (3) Data about the manufacturing process. After submitting the IND, the sponsor must wait 30 days. Count down the days before the start of any clinical trials. The Food and Drug Administration (FDA) has the authority to verify the IND for safety throughout this period to guarantee that it is secure. The criteria for the content and form of an IND application are laid forth in Section 312 of the 21 code of federal regulations. If you wish to perform a clinical review, you need submit a "Investigator New Project" application. Fill out the "Drug Application" form in the sequence listed below [17].

- $\quad$ FDA Form 1571

- Tables of contents

- $\quad$ Statement of intent and investigational strategy

- Sponsor's brochure

- Protocols are a set of rules that govern how

- Data on chemistry, manufacturing, and control.

- Data on pharmacology and toxicology.

- Previous people/human experience. 
- Additional information.

\subsection{New Drug Application (NDA)}

A New Drug Application must be submitted in order to market a new medicine (drug) in the United States. An NDA contains all of the information provided in the IND, as well as the results of clinical trials showing safety and efficacy. The FDA will begin the review process 60 days after the application, providing a non-disclosure agreement in NDA format and contents for a set of two. The application is divided into two sections: (1) archival copy and (2) review.

Archival Copy: it includes copies of tabulations and clinical trial case report forms, and it acts as a reference source for FDA reviewers looking for details not included in the review copy.

Review Copy: Each technical section is bound separately in each folder as a review copy. Each technical section should include the following: 2.1) Index, 2.2) FDA form $356 \mathrm{~h}$ (copy). 2.3) A duplicate of the cover letter 2.4) Authorization letters 2.5) A copy of the application summery is required.

The FDA will meet with the sponsor at least twice: once at the conclusion of phase 2 clinical trials and again before an NDA is filed, referred to as a pre-NDA meeting. The analysis committee will look into it. The study's finding and decide whether or not to accept the proposal the application [18].

\subsection{Abbreviated New Drug Application (ANDA)}

ANDA is used for goods with the same or similar active components, dose type, and strength, as well as the same or similar administration and usage routes. As well as choosing a product that has been proved to be safe and dependable. When a product's patent expires and the firm wants to sell it in order to advertise its replica, this is true. These drugs are known as generics, and they must meet bio and pharmacological comparable standards. The Office of Drug Evaluation and Research of the Center for Drug Evaluation and Research receives an ANDA. In the Generic Drugs category, it has been examined and approved [19].

\subsection{Supplemental New Drug Application (SNDA) [20]}

After the NDA or ANDA has been granted, any substantial modifications in the conditions mentioned in the applications must be acknowledged by filing a New NDA or ANDA. The CDER must approve a supplemental NDA or ANDA that includes modifications like as packaging or ingredients. This category contains new-uses approvals of previously approved medications, which are a better breakthrough than new-uses approvals of previously approved drugs since they require fewer resources to examine. For the first time, approvals are required.

\section{Common technical documents (CTD)}

The common technical documents (CTD) are a collection of application requirements for the registration of medicine and design that may be utilized throughout Europe, the United States (US), and Japan. It is an international accepted format for constructing an application for a novel medication intended to be presented to regional regulatory bodies in the participating country.

CTD is a collaborative effort of three regulatory agencies: the European Medicines Agency (EMA), the Food and Drug Administration (FDA), and the Ministry of Health, Labor, and Welfare in the United States (MHLW, Japan). The CTD was kept up to date by the International Council on Harmonization (ICH) of technical requirements for pharmacological approval for human use. CTD is a globally recognized format for organizing technical requirements for submission to regulatory authorities [10].

\section{Objectives of CTD}

- The main objective is to reduce the time required and resources used to compile applications.

- It will help to the preparation of electronic submissions of application.

- To facilitate simultaneous submission in three regions.

- It will help to exchange of regulatory information and consequently ensure faster availability of new medicine 


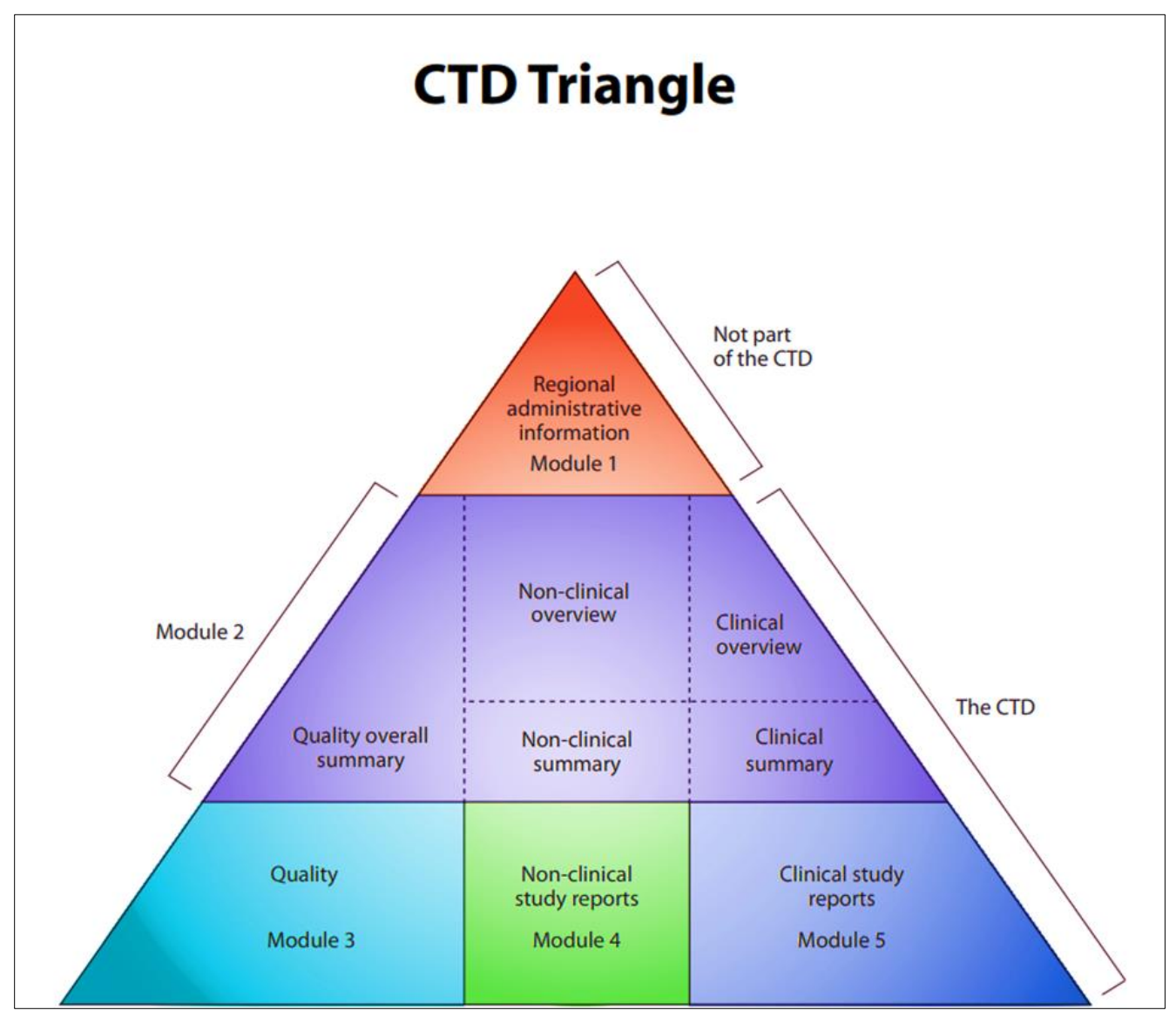

Figure 2 The CTD triangle. The Common Technical Document is organized into five modules. Module e 1 is region specific and modules 2, 3, 4 and 5 are intended to be common for all regions.

\section{Modules of CTD}

It can be organized into 5 Modules:-

- Module 1: administrative and prescribing information

- Module 2: common technical documents CTD summaries

- Module 3: Quality data

- Module 4: Nonclinical study reports

- Module 5: Clinical study reports

The format should be clearly readable and understandable manner e.g. font size should be 12 , font should be in Times New Roman and page layout for EU and Japan - A4 paper and for U.S.A. - $8.5 \times 11$. The margin for the left hand should be large enough and the information should be not be out of sight and uncertain after binding.

- The common technical document are details and surely acceptable by the regulatory authority.

- The document can be easily review by the reviewer.

- The submitted document should be dated and signed.

- The document should be properly labelled as per the regulatory guidelines of the country.

- Documents that can be required should be submitted as per the checklist to avoid rejection of the application or queries which in turn speed up the review process and approval.

- The justification for certain tests should be properly mentioned and supportive documents should be attached.

- Once dossier is prepared before sending it has to checked and verified for any mistakes.

- In the report of the clinical study as per module $5 \mathrm{CRF}$, all the study reports should be attached with the documents. 
- Some of the authorized countries ask for the validation certificates.

- If there are changes in any batch that should be mentioned and justify.

\subsection{Module -1 administrative and prescribing information}

It is the region specific not the part of CTD. It gives administrative as well as prescribing information. This document is specific to each region e.g. application form, proposed label use for on the region. General information regarding the module 1

- Gives general information about covering letter and content of comprehensive table

- Gives administrative information such as, short information about the applicant company. Gives the correctly completed and signed the application in the form 44 and treasury challan. It gives legal and critical documents as like copy of clinical trial/ BE., there is no objection letters issued by the CDSCO, Batch release certificate that can be issued by national Regulatory Authorities. e.g. for the production and marketing of finished product, in addition to the above-mentioned documents. Such as Copy of existing manufacturing license in Form 25 / 28, Copy of Form-29, Certificate of Analysis, Coordinates related to the application.

- Provides general information on finished drug products.

- Provides regulatory status in different countries.

- Provides internal price of the finished drug product followed in the countries

- It can also provide a brief information of the manufacturer's research activities.

- It can also provide a brief information manufacturer's business activity in national as well as international market.

- Provides details regarding involvement of the experts

- It gives information about sample of drug product and promotional materials.

\subsection{Module -2 CTD Summaries}

Content of module 2:

- Table of content (comprehensive).

- Introduction (general introduction to the pharmaceutical, including its pharmacological class, mode of action, and proposed clinical used.)

- Qualities Overall summaries (The Qualities Overall Summaries (QOS) are an outline of the data presented in module 3).

- Non-clinical overview.

- Clinical overview.

- Non-clinical summaries.

- Clinical summaries

\subsubsection{Non-clinical overview}

In the non-clinical overview there is Implications of nonclinical findings for the safe use of the pharmaceutical

- Introduction and GLP statement

- Overview of the Non-Clinical Testing Strategy

- Pharmacology.

- Pharmacokinetics.

- Toxicology

- Integrated Overview and Conclusions

- List of Literature References

\subsubsection{Clinical overview}

In the clinical overview there is an overview of the clinical data were analysed.it also provides a brief overview of the new clinical findings. Analyses the benefits and risks of the medicinal products in its intended use [21]. 
- $\quad$ Product Development Rationale.

- Overview of Biopharmaceutics.

- Overview of Clinical Pharmacology

- Overview of Efficacy

- Overview of Safety

- Benefits and Risks Conclusions

- Literature References

\subsubsection{Non-clinical summaries}

The non-clinical summary can be written and tabulated format. It includes Summary of pharmacokinetic, pharmacological and toxicology studies with in-vivo/In-vitro, species, route and duration and effect related to appropriate age and gender.

\subsubsection{Clinical summaries}

This section is intended to provides a detailed, factual summarization of all of the clinical information in the CTD this include information provided in clinical study reports, information obtained from any analyses for which full reports have been included in Module 5 and post-marketing data for products that have been marketed in other regions [22].

The clinical summary includes

- Biopharmaceutic Studies and Associated Analytical Methods.

- Clinical Pharmacology Studies

- Clinical Efficacy

- Clinical Safety

- Literature References

- Synopses of Individual Studies

\subsection{Module 3 - quality data}

In this module the quality section of common technical documents (M4Q) provides a compatible structure and format for presenting the chemistry, manufacturing and control (CMC) information in the registration dossier.

The module includes

- $\quad$ Table of content

- $\quad$ Body of data

- Literature references

- $\quad$ Body of data

$\checkmark \quad$ Drug Substance

$\checkmark$ General Information

$>$ Nomenclature

$>$ Structure

$>$ General Properties

$\checkmark$ Manufacture

$>$ Manufacturer Details 
$>$ Description of Manufacturing Process and Process Controls

Control of Materials Control of Materials

$>$ Controls of Critical Steps and Intermediates

$>$ Process Validation and/ or Evaluation

$>$ Manufacturing Process Development

$\checkmark$ Characterization

$>$ Elucidation of structure and other Characteristics

$>$ Impurities

$\checkmark$ Control of Drug Substance

$>$ Specification of Drug Substance

$>$ Analytical Procedures

$>$ Validation of Analytical Procedures

$>$ Batch Analyses

$>$ Justification of Specification

$\checkmark$ Reference Stand Reference Standards or Materials or Materials

$\checkmark \quad$ Container Closure System

$\checkmark$ Stability

$>$ Stability Summary and Conclusions

> Post-approval Stability Protocol and Stability Commitment

$>$ Stability Data

- Drug Product

$\checkmark$ Description and Composition of the Drug Product

$\checkmark$ Pharmaceutical Development

$>$ Components of Drug Product

$>$ Drug Product Drug Product

$>$ Manufacturing Process Development

$>$ Container Closure System

$>$ Microbiological Attributes

$>$ Compatibility

- Manufacture 
$\checkmark \quad$ Manufacturer

$\checkmark \quad$ Batch Formula Batch Formula

$\checkmark$ Description of Manufacturing Process and Process Controls

$\checkmark$ Controls of Critical Steps and Intermediates

$\checkmark$ Process Validation Process Validation and /or Evaluation

- Control of Excipients

$\checkmark$ Specifications

$\checkmark \quad$ Analytical Procedures Analytical Procedures

$\checkmark \quad$ Validation of Analytical Procedures

$\checkmark \quad$ Justification of Specifications

$\checkmark$ Excipients of Human or Animal Excipients of Human or Animal Origin

$\checkmark \quad$ Novel Excipients

- Control of Drug Product

$\checkmark \quad$ Specification of Drug Product

$\checkmark$ Analytical Procedures Analytical Procedures

$\checkmark \quad$ Validation of Analytical Procedures

$\checkmark \quad$ Batch Analyses

$\checkmark$ Characterization of Impurities

$\checkmark \quad$ Justification of Specification

- $\quad$ Reference Standards or Materials

- Container Closure System

- $\quad$ Stability

$\checkmark \quad$ Stability Summary and conclusion

$\checkmark$ Post-approval Stability Protocol and Stability Commitment

$\checkmark$ Stability Data

\subsection{Module - 4 Non-Clinical Study Reports}

Module 4 describes the format and organization of the nonclinical (pharmaco-toxicological) data relevant to the application.

- Table of contents

- Study Reports 
$\checkmark \quad$ Pharmacology

$>$ Primary Pharmacodynamic

$>$ Secondary Pharmacodynamic

$>$ Safety pharmacology

$>$ Pharmacodynamic drug interaction

$\checkmark$ Pharmacokinetics

$>$ Analytical Methods and validation Reports

$>$ Absorption

$>$ Distribution

$>$ Metabolism

$>$ Excretion

$>$ Pharmacokinetic Drug Interactions

$>$ Other Pharmacokinetic studies

$\checkmark \quad$ Toxicology

$>$ Single-dose toxicity dose toxicity

$>$ Repeat-dose toxicity

$>$ Genotoxicity

$>$ Carcinogenicity

$>$ Reproductive and developmental

$>$ Local tolerance

$>$ Other toxicity studies other toxicity studies

$\checkmark \quad$ Literature References

\subsection{Module - 5 clinical study report}

- Table of Contents

- Tabular Listings of All Clinical Studies

- Clinical Study Reports

$>$ Bioavailability (BA) study Reports

$>$ Comparative BA and Bioequivalence study reports

$>$ In-vitro In-vivo Correlation study reports 
$>$ Reports of Bioanalytical and Analytical methods

$>$ Plasma Protein Binding Study Plasma Protein Binding Study Reports

$>$ Reports of Hepatic metabolism and Drug Interaction Studies

$>$ Reports of Studies Using human Biomaterials

$>$ Healthy Subject PK and Initial Tolerability study reports

$>$ Patient PK and Initial Tolerability study reports.

$>$ Intrinsic Factor PK study reports

$>$ Extrinsic Factor PK study reports

$>$ Population PK study reports

$>$ Healthy subject $\mathrm{PD}$ and $\mathrm{PK} / \mathrm{PD}$ study reports

$>\quad$ Patient $\mathrm{PD}$ and $\mathrm{PK} / \mathrm{PD}$ study reports

$>$ Study reports of controlled clinical studies

$>$ Study reports of uncontrolled clinical studies

$>$ Reports of Analyses of data from more than one study

$>$ Other clinical study reports

$\checkmark$ Reports of Post-Marketing Experience

$\checkmark \quad$ Case report forms and Individual patient listings

- $\quad$ List of Key Literature References

\section{Electronic common technical document (eCTD)}

The eCTD is an electronic equivalent to the CTD. According to the regulatory perspective "The eCTD is defined as an interface for industry to agency transfer of regulatory information while at the same time taking into consideration the facilitation of the creation, review, lifecycle management and archival of the electronic submission". The standard, and many of the modules have been agreed upon by the main worldwide agencies. Once a submission is sent in eCTD format all future submissions for the application should be in eCTD format.

The eCTD according to the technical perspective it is a structured set of common folders structure containing PDFs and SAS files (Statistical Analysis Software) on a CD/DVD (Can also be submitted through Agency web portals). The eCTD backbone is an XML file (Extensible Markup Language) representing the structure of the submission, it also includes links to files and other metadata such as check sum information. It is the electronic common technical documents, is an electronic format where the information and documents are submitted to the authorized regulatory body electronically by using a software. It is an electronic document that compiled by a pharmaceutical company or the agency in compliance with the European legislation and guidelines in order to seek a marketing or any amendments.

The eCTD submission is for the application, supplements, reports, master formulae, etc. the eCTD format is understandable and successfully applying in the submission is the biggest barrier. The application and promoter may be facing the problem when the document does not as per the required format because of the application should be reject [23]. 


\subsection{Benefits of eCTD}

The eCTD should be easy to distribute and review, more efficient use of resources, less cost and stress to the organization. The eCTD should have highly organized electronic table of content, searchable and self-validating.

The implementation of eCTD for FDA starts from 1 Jan 2008, then eCTD become CDER's standard for the electronic submission. The FDA has made it mandatory for all electronic submission to be in eCTD format from 2007-08. However the paper copies are still accepted. The number of submissions of ANDA to FDA has increased from 72 in the year 2006 to 1550 in the year 2009. To maintain the huge data of the entire submission like information about submitting and receiving organization, manufacturer, ID's, etc. and documents [24].

\subsection{Common format for eCTD}

- $\quad$ Narrative: Portable Document Format (PDF) [Calibri 12].

- $\quad$ Structure: Extensible Markup Language (XML).

- Graphic: Use PDF, whenever PDF is not supporting, use Joint Photographic Experts Group (JPEG), Portable Network Graphics (PNG), Scalable Vector Graphics (SVG) and Graphic Interchange Format (GIF).

- $\quad$ Font size 9 and 10 are suggested for tables

The regulatory content information:

Table 3 The regulatory content information

\begin{tabular}{|l|l|l|}
\hline \multicolumn{1}{|c|}{ Region } & \multicolumn{1}{|c|}{ Internet address } & \multicolumn{1}{|c|}{ Electronic mail contact. } \\
\hline European Union & http://www.emea.europa.eu & esubmission@emea.europa.eu \\
\hline Food and drug administration USA & $\begin{array}{l}\text { www.fda.gov/cber } \\
\text { www.fda.gov/cder }\end{array}$ & $\begin{array}{l}\text { esubprep@fda.hhs.gov } \\
\text { esub@fda.hhs.gov }\end{array}$ \\
\hline $\begin{array}{l}\text { Ministry of Health, Labour and } \\
\text { Welfare, Japan }\end{array}$ & $\begin{array}{l}\text { http://weww.mhlw.go.jp } \\
\text { http://www.pmda.go.jp }\end{array}$ & ectd@pmda.go.jp \\
\hline Health Canada & http://www.hc-sc.gc.ca & ereview@hc-sc.gc.ca \\
\hline
\end{tabular}

Software used in eCTD management:

Table 4 Software used in eCTD management

\begin{tabular}{|c|l|}
\hline Sr.no. & \multicolumn{1}{|c|}{ Software } \\
\hline 1 & eCTDXPress-Image solution-http://www.imagesolutions.com \\
\hline 2 & eCTDXPress-Image solution-http://www.imagesolutions.com \\
\hline 3 & Data farm, http://www.datafarminc.com \\
\hline 4 & Take solution : www.PharmaReady.com \\
\hline 5 & MasterControl submission Gateway ${ }^{\mathrm{TM}}$-Master Control, http://www.mastersolution.com \\
\hline 6 & Lorenz Life Science : www.lorenz.com \\
\hline
\end{tabular}

\section{Conclusion}

The pharmaceutical industry is one of the most heavily regulated industries on the planet. Regulatory Governing Bodies (Authorities) have been formed all around the globe to ensure that medicines for human use satisfy global standards of quality, effectiveness, and safety. For example, FDA, TGA, CDSCO, EMEA, and others. The role of regulatory affairs is to design and implement regulatory strategies to ensure that the drug development team's combined efforts result in a product that is approved by regulatory bodies. Drug regulatory affairs is a dynamic subject that encompasses both scientific and legal elements of drug research, such as NDA, INDA, and ANDA. By following SOPs, ICH standards, and WHO - GMP guidelines, regulatory affairs experts assist the firm in avoiding problems like as poorly kept records, poor 
data presentation, and incorrect scientific thinking. Regulatory affairs plays a key role in all elements of drug regulations since the successful adoption of any new pharmaceutical product, new molecular entity, takes around 10 to 15 years and involves a significant amount of time and money.

\section{Compliance with ethical standards}

\section{Acknowledgments}

We would like to thanks Mr. Sarang Muley (Drug regulatory affair department, Aurobindo Pharma) for guidance about International regulatory affair guideline and submission protocol. We also thankful to Sachin Shinde (Department of pharmacology, shri R. D Bhakt College of pharmacy, Jalna) give guidance about to drafting manuscript, regulatory guideline.

\section{Disclosure of conflict of interest}

No conflict of interest.

\section{References}

[1] Writing SG-L-M. undefined. Good regulatory practice and the role (s) of a regulatory affairs professional. Taylor Fr [Internet]. Dec 2013; 22(4): 279-81.

[2] Kumar S, Panwar R. US-J of R D in, 2013 undefined. Regulatory affairs in the pharmacy curriculum. ijrdpl.com [Internet].2021; 2(6): 690-8.

[3] Vanaja K, Rani RHS. Design of experiments: Concept and applications of plackett burman design. Clin Res Regul Aff [Internet]. Jan 2007; 24(1): 1-23.

[4] Wood KL. The medical dictionary for drug regulatory affairs (MEDDRA) project. Pharmacoepidemiol Drug Saf. 1994; 3(1): 7-13.

[5] safety KW-P, drug, undefined. The medical dictionary for drug regulatory affairs (MEDDRA) project. Wiley Online Libr [Internet].1994;

[6] Roshan K. (GJRA) JA-GJFRA, 2018 undefined. ROLE OF REGULATORY AFFAIRS IN PHARMACEUTICAL COMPANY: AN OVERVIEW. wwjournals.org [Internet].2018.

[7] Drago D, Yap M. Regulatory OE-CR and, undefined. Increasing the odds of effective drug development: Elevating regulatory affairs professionals to strategic partners. Taylor Fr [Internet]. 2016.

[8] Affairs BK-IJ of DR, 2013 undefined. Overview of Drug Regulatory Affairs and Regulatory Profession. researchgate.net [Internet]. 2013; 2013(1): 1-4.

[9] Information MX-CMD. undefined. Overview of Medical Device Regulatory Affair Professional's Training Abroad and its Implication for China. en.cnki.com.cn [Internet]. 2009.

[10] Mahaparale S, Desai B. Role and overview of drug regulatory affairs in pharmaceutical industry with implementation of CTD and ECTD. Sonali al World J Pharm Res [Internet]. 2018; 7.

[11] Sutar M, Gawhane D. of CT-IJ. undefined. Drug Regulatory Approval Process an Comparative Requirement of Common Technical Documents (CTD) in Europe, USA and India in Coordination with Drug .... sites.google.com [Internet].2013.

[12] Dalal K, Ganguly B. diagnostic AG-J of clinical and, 2016 undefined. Assessment of rationality of fixed dose combinations approved in CDSCO list. ncbi.nlm.nih.gov [Internet]. 2016.

[13] Evangeline L, Mounica N. VR-TP. undefined. Regulatory process and ethics for clinical trials in India (CDSCO). researchgate.net [Internet]. 2017.

[14] Deep A, Khurana G, Research JK. Trials C. undefined. Comparison of Basic Regulatory Requirements for Generic Drug Products Registration in CIS and Latin American Countries. ingentaconnect.com [Internet]. 2012.

[15] Kumar V. Comparative Study of the Regulatory Guidelines for Clinical Trials in Regulated and Semi-Regulated Countries. 2016. 
[16] Zivin JA. Acute stroke therapy with tissue plasminogen activator (tPA) since it was approved by the U.S. Food and Drug Administration (FDA). Ann Neurol. 2009 Jul; 66(1): 6-10.

[17] Drago D, Yap M, Ekmekci O. Increasing the odds of effective drug development: Elevating regulatory affairs professionals to strategic partners. Clin Res Regul Aff. 1 Oct 2016; 33(2-4): 59-65.

[18] Reynolds I, Rising J, AC-J internal, undefined. Assessing the safety and effectiveness of devices after US Food and Drug Administration approval: FDA-mandated postapproval studies. jamanetwork.com [Internet]. 2014.

[19] Kane R, Farrell A, Sridhara R, Research RP-CC, undefined. United States Food and Drug Administration approval summary: bortezomib for the treatment of progressive multiple myeloma after one prior therapy. AACR [Internet]. 2006.

[20] Downing N, Shah N, Aminawung J, Jama AP-, undefined. Postmarket safety events among novel therapeutics approved by the US Food and Drug Administration between 2001 and 2010. jamanetwork.com [Internet]. 2017; 317(18): 1854-63.

[21] PharmaTutor YV-, undefined. Regulatory Affair: Link between company and Government Authority. pharmatutorjournal.com [Internet]. 2014.

[22] Barber CM. VP Regulatoy, Quality Assurance, Medical \& Clinical Affairs. FASEB J. Apr 2010; 24(S1).

[23] Suchanek A, Ostermann H. The Electronic Common Technical Document (eCTD): An International Pro/Con Analysis of the Pharmaceutical Product Electronic Submission Process. Drug Inf J. Jan 2012; 46(1): 124-39.

[24] Cartwright AC. The electronic common technical document: From design to submission. Int J Pharm Med. 2006; 20(3): 149-58. 